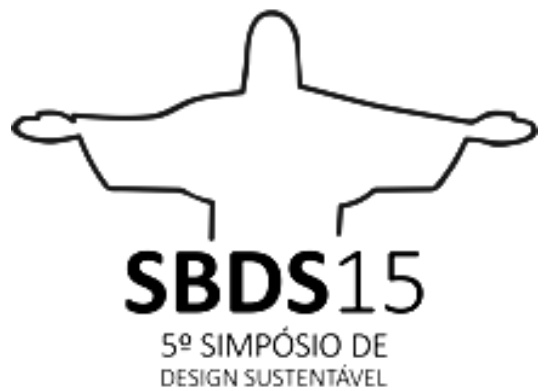

Rio de Janeiro, 11 de novembro a 13 de novembro de 2015

\title{
ARTESANATO E SUSTENTABILIDADE: em busca de alternativas para a Cerâmica do Cabo de Santo Agostinho.
}

\author{
Ana Maria Queiroz de Andrade \\ Universidade Federal de Pernambuco \\ anamariadeandrade@gmail.com \\ Virginia Pereira Cavalcanti \\ Universidade Federal de Pernambuco \\ cavalcanti.virginia@gmail.com \\ Germannya D'Garcia Silva \\ Universidade Federal de Pernambuco \\ germannyadgarcia@gmail.com \\ Tibério Cesar Macedo Tabosa \\ Laboratório de Design O Imaginário - UFPE \\ ttabosa@hotmail.com
}

\begin{abstract}
Resumo: $\mathrm{O}$ artigo apresenta as experiências do Laboratório de Design $\mathrm{O}$ Imaginário, nos últimos dois anos, junto aos ceramistas do Cabo de Santo Agostinho, Pernambuco, Brasil. A sustentabilidade é o recorte escolhido para explicitar as interfaces da relação design-artesanato com o meio ambiente, articulação com a sociedade e o fortalecimento do grupo. A pesquisa - ação norteou as atividades patrocinadas pelo Programa Petrobras Desenvolvimento \& Cidadania ${ }^{1}$ e relacionou mercado, gestão, design, produção e comunicação para buscar a sustentabilidade do Centro de Artesanato Arqto. Wilson de Queiroz Campos Júnior, Cabo, Pernambuco.
\end{abstract}

Palavras-chave: sustentabilidade, artesanato, design, cerâmica artesanal.

\footnotetext{
${ }^{1}$ A Petrobras tem compromisso com a geração de riqueza, com a ampliação da soberania e com a construção de um país onde todos os brasileiros e brasileiras, reconhecidos e respeitados em suas diferenças, tenham direito às mesmas oportunidades de acesso aos benefícios do desenvolvimento. Para aqueles que compartilham do compromisso da Petrobras com a justiça social, estão abertas as inscrições da Seleção Pública de Projetos Sociais 2012 do Programa Petrobras Desenvolvimento \& Cidadania, que destinará $\mathrm{R} \$ 145.000 .000,00$ (cento e quarenta e cinco milhões de reais) para apoiar projetos voltados para a superação da pobreza e da desigualdade no país. http://dec.petrobras.com.br/apresentacao/17 Acesso em 17 de agosto de 2015.
} 


\begin{abstract}
:
This paper presents $O$ Imaginário Lab's experiences, in the last two years, along with the ceramic artisans from Cabo de Santo Agostinho, Pernambuco, Brazil. The Sustainability is the chosen perspective to explain the interfaces between design-crafts to the environment, linkage with society and the strengthening of the artisans' group. The action-research methodology was used to guide the activities, sponsored by Petrobras Development \& Citizenship Program, related market management, design, production and communication for sustainability the Centro de Artesanato Wilson Campos Júnior.
\end{abstract}

Keywords: sustainability, handicraft, design, ceramic craft

\title{
1. INTRODUÇÃO
}

Ao longo de 12 anos, a relação entre a cerâmica artesanal do Cabo de Santo Agostinho e o Laboratório de Design da Universidade Federal de Pernambuco - O Imaginário estimula pesquisas e atividades de extensão nas áreas de design e artesanato. $O$ artigo apresenta as experiências vivenciada nos últimos dois anos, a partir do recorte da sustentabilidade, e discute os aspectos que impactaram na relação com o meio ambiente, na articulação com representantes da comunidade e no fortalecimento do grupo de artesãos que atuam no Centro de Artesanato Arqto. Wilson de Queiroz Campos Junior.

O referencial teórico utilizado está baseado nos conceitos que associam cultura, desenvolvimento e sustentabilidade bem como no entendimento do design enquanto instrumento facilitador para compreender os desafios contemporâneos.

Ao considerar os território físico e político e os contextos das relações de poder, a pesquisa utiliza uma abordagem dialética e é construída a partir da pesquisa-ação.

O patrocínio do Programa Petrobrás Desenvolvimento e Cidadania garantiu condições de financiamento que contemplaram o envolvimento de artesãos, técnicos, professores e estudantes para realizar atividades voltadas para produção, mercado, design, comunicação e gestão durante dois anos consecutivos. Tal condição impactou nos experimentos que envolveram tecnologia de materiais e técnicas de produção, na ampliação e consolidação dos artesãos enquanto grupo e refletiu positivamente no acesso dos produtos ao mercado, construindo avanços econômicos significativos.

\section{DESENVOLVIMENTO}

\subsection{Tecnologia e sustentabilidade: o desafio para a atuação no Cabo de Sto. Agostinho}

A aproximação do Laboratório O Imaginário à comunidade de ceramistas do Cabo de Santo Agostinho no ano 2003 foi motivada por questões ambientais, provocadas pela necessidade de vitrificação ${ }^{2}$ da cerâmica e assim atender aos requisitos dos produtos utilitários de mesa, o segmento de mercado mais promissor naquela época. A solução encontrada pelos ceramistas foi utilizar esmalte cerâmico ${ }^{3}$ contendo zarcão ${ }^{4}$ para baixar a temperatura de queima, pois os fornos eram alimentados a lenha (até $850^{\circ} \mathrm{C}$ ). Entretanto, tal processo é inadequado, pois o uso de chumbo é tóxico e prejudicial a saúde tanto de quem produz quanto a de quem utiliza um produto vitrificado com esse tipo de material

\footnotetext{
2 processo de impermeabilização da superfície cerâmica com a aplicação de esmaltes e queima em temperatura constante.

${ }^{3}$ O esmalte cerâmico é resultado da interação de três componentes básicos: a sílica, formadora de vidros, os fundentes, cuja função é baixar a temperatura de fusão da sílica, além de modificar a textura e as cores dos esmaltes, e, por fim, a alumina, que influencia a viscosidade e torna o esmalte mais refratário.

${ }^{4}$ Mineral a base de Chumbo vermelho, venenoso, que atua como fundente, baixando a temperatura de fusão da sílica.
} 
Para reverter a situação o Laboratório, obedecendo os princípios do respeito às diferenças, da valorização da cultura local e da construção de um projeto coletivo, direcionou a sua atuação à realidade e, neste caso, reconheceu como grande mobilizador o argumento da tecnologia.

Os esforços para garantir uma boa queima (fornos de alta temperatura) e o beneficiamento da matéria-prima (uso de marombas e tanques de decantação para eliminação de resíduos), para evitar quebras e diminuir perdas na produção, foram objetos de projetos elaborados pelo Laboratório para diferentes financiadores.

Em paralelo aos investimentos em equipamentos de infraestrutura, a preocupação com a preservação da jazida de argila natural instigou pesquisas para composições de massa com adição de resíduos industriais cerâmicas. A preocupação transformada em atitude fez crescer o interesse dos artesãos em buscar oportunidades de aproveitamento de barro oriundo de obras de terraplanagem do entorno, fazendo crescer a relação de parceiros locais

A articulação com a Prefeitura garantiu em 2007 a construção de um espaço físico, o Centro de Artesanato Arqto. Wilson de Queiroz Campos Junior, projetado para atender as necessidades de produção, com áreas para modelagem, beneficiamento, esmaltação e queima, além de apoio administrativo e de serviços, situado em área privilegiada, próxima ao maior Shopping Center local.

Muito embora a intervenção tenha enfatizado inicialmente a tecnologia e por conseguinte a produção, o modelo desenvolvido pelo Laboratório O Imaginário (Figura 01) integra ações relacionadas a produção, mercado, gestão, design, comunicação para buscar alternativas que ampliem a geração de renda, a consolidação e autonomia da comunidade artesã.

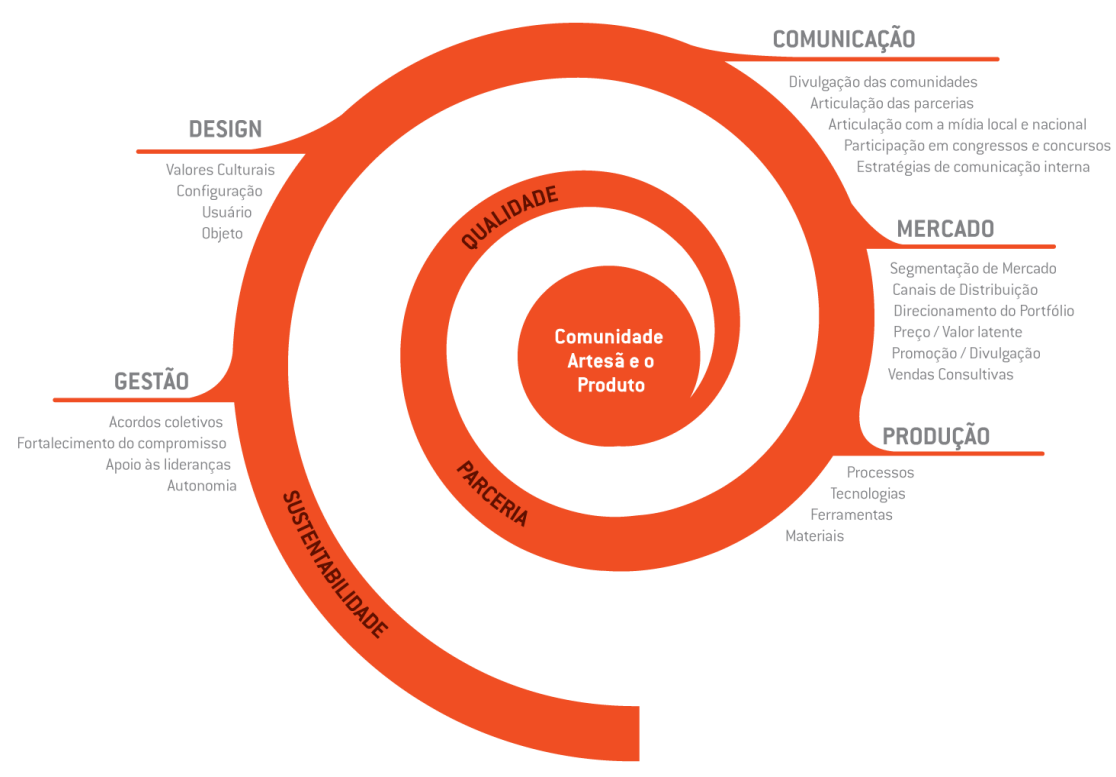

Figura 1 - Modelo de atuação do Laboratório O Imaginário para a produção artesanal.

Fonte: ANDRADE; CAVALCANTI, 2006.

Para compreender a realidade o modelo faz uso de suas características dinâmicas, envolvendo além da comunidade artesã, os poderes locais e os parceiros. Por estar situado na Universidade o Laboratório 0 Imaginário conta com o apoio de diversos departamentos garantindo uma abordagem de múltiplas perspectivas: social, ambiental, técnica e política na busca da sustentabilidade de comunidades artesãs atendidas. Esse é sem dúvida uma aspecto que diferencia a implementação do modelo pois exige uma equipe com formação diversificada, multidisciplinar, vocacionada para a pesquisa e a extensão, com capacidade de articulação e autonomia. Essas características permitem que as ações não sejam interrompidas quando há alternâncias de poder, principalmente o âmbito municipal. E esse é um aspecto delicado, uma vez que a gestão dos municípios, em geral, tem dificuldade de associar cultura e 
desenvolvimento, limitando o investimento em cultura a ações pontuais, desarticuladas daquelas mais estruturadoras. Há também de se considerar que a necessidade de tempo para consolidação dos grupos de artesãos é, em geral, muito maior do que aquele dos governos.

Os diálogos entre consumo e produção, tradição e inovação alimentam a relação design-artesanato estabelecida pelo modelo de intervenção de design no artesanato apresentado e, ao valorizar os bens culturais e os seus territórios, potencializa os recursos locais em favor da comunidades artesãs. Este direcionamento tem o suporte de pesquisadores que reconheceram a importância do patrimônio cultural e da valorização da cultura na formulação de modelos de desenvolvimento.

\subsection{Artesanato e design: desenvolvimento e sustentabilidade.}

Para discutir conceitos de desenvolvimento e sustentabilidade no contexto do artesanato o artigo reconhece a pertinência de autores que acreditam no diálogo equilibrado entre desenvolvimento e cultura para, a um só tempo, buscar solução e revelar problemas. Essa abordagem implica no reconhecimento de uma realidade complexa, ambivalente que se revela nas inconsistências do cotidiano. Para intervir na realidade as politicas de desenvolvimento fazem uso de argumentos da cultura para identificar convergências de interesse e equacionar crescimento econômico, meio ambiente e inclusão social. Esforço que se traduz na valorização dos direitos de representação, equidade, respeito as diferenças e solidariedade.

No Brasil, o conceito de desenvolvimento marcado fortemente pela dimensão cultural é atribuído ao economista Celso Furtado. A sua afirmação de que "sou da opinião de que a reflexão sobre a cultura brasileira deve ser o ponto de partida para o debate sobre as questões de desenvolvimento" (FURTADO, apud D'AGUIAR, 2013, pág. 203) apresenta com precisão o seu ponto de vista. Seus estudos deram origem a criação da Superintendência do Desenvolvimento do Nordeste - SUDENE, nos anos 60, que considerou a importância das manifestações culturais e do artesanato como atividade econômica de impacto para a geração de renda na região.

Sob a perspectiva da cultura, Aloísio Magalhães artista e designer gráfico que teve importante papel na cena política e cultural brasileira, afirmava "Não tem sentido a memória apenas para guardar o passado. (...) A tarefa de guardar o patrimônio, ao invés de cuidar do passado, é essencialmente uma tarefa de refletir sobre o futuro"(MAGALHÃES, 1997, pág. 22). Em sua famosa provocação "E, Triunfo?" demonstrava junto aos economistas, sua preocupação com o papel dos bens culturais no processo de desenvolvimento do país.

Ao afirmar "o universal não é igual" Aloisio Magalhães sinaliza sua compreensão da relação localglobal marcada pelo pluralismo e respeito as diferenças, valorizando o poder criativo local, principalmente naqueles procedentes da cultura popular: "é a partir deles que se afere o potencial, se reconhece a vocação e se descobrem valores mais autênticos da nacionalidade".

Reforçando argumentos apresentados, agora com o enfoque na biodiversidade, o Prof. Ignacy Sachs aponta a necessidade de estratégias de desenvolvimento negociadas para contratar (....) "um desenvolvimento endógeno (em oposição à transposição mimética de paradigmas alienígenas), autossuficiente ( em vez de dependente), orientado para as necessidades (em lugar de direcionado pelo mercado) , em harmonia com a natureza e aberto às mudanças institucionais. (SACHS, 2009, pag. 53).

Essa alternativa está fundamentada na harmonização dos objetivos sociais, ambientais e econômicos, denominada desenvolvimento sustentável ${ }^{5}$ ou ecodesenvolvimento ${ }^{6}$, que remetem a estratégias economicamente eficazes, ecologicamente prudentes e socialmente equitativas, como afirma Sachs (SACHS, 2007). Ao mesmo tempo, o autor adverte que "estamos sendo desafiados a formular planos

\footnotetext{
${ }^{5}$ O relatório Brundtland, de 1987, da Comissão. Mundial sobre Meio Ambiente e Desenvolvimento, retoma o conceito de Desenvolvimento Sustentável, dando-lhe a seguinte definição: "desenvolvimento que responde às necessidades do presente sem comprometer as possibilidades das gerações futuras de satisfazer suas próprias necessidades" (RAYNAUT e ZANONI, 1993, apud MONIBELLER 1993, pág.135).

${ }^{6}$ Trata-se, portanto, o Ecodesenvolvimento, de um projeto de Civilização, na medida em que evoca: um novo estilo de vida; conjunto de valores próprios; conjunto de objetivos escolhidos socialmente; e visão de futuro (Quem? apud MONIBELLER1993, pág. 133). https://periodicos.ufsc.br/index.php/economia/article/viewFile/6645/6263. Acesso em 18 de novembro de 2014.
} 
de ação muito mais concretos e precisos em termos de recursos e prazos - e isto sem esperar mais por avanços significativos no âmbito das negociações internacionais" (op.cit, pág. 23).

A perspectiva do desenvolvimento sustentável portanto, reconhece a capacidade das comunidades de interpretar seus próprios problemas, sua base de recursos naturais, suas necessidades e aspirações. (Ossa, 1989; Sauvé, 1996; Friedmannn, 1999; Gadgil, 1999; Morin, 1995, apud VIEIRA, 2007). Comungando com esses princípios e investindo na construção de metodologias de planejamento para o desenvolvimento local, o pesquisador Sérgio Buarque afirma que:

"O desenvolvimento local pode ser conceituado como um processo endógeno de mudança, que leva ao dinamismo econômico e à melhoria da qualidade de vida da população em pequenas unidades territoriais e agrupamentos humanos. Para ser consistente e sustentável, o desenvolvimento local deve mobilizar e explorar as potencialidades locais e contribuir para elevar as oportunidades sociais e a viabilidade e competitividade ${ }^{7}$ da economia local; ao mesmo tempo, deve assegurar a conservação dos recursos naturais locais, que são a base mesma das suas potencialidades e condição para qualidade de vida da população local. Esse empreendimento endógeno demanda, normalmente, um movimento de organização $e$ mobilização da sociedade local, explorando as suas capacidades e potencialidades próprias, de modo a criar raízes efetivas na matriz socioeconômica e cultural da localidade." (BUARQUE, 2004, pag. 25)

A prática o desenvolvimento local requer um ambiente de inovação e aprendizagem social, fruto de uma maior consciência da sociedade acerca dos problemas sociais e ambientais. É sem dúvida um contexto complexo ${ }^{8}$ e a sua prática exige instrumentos, como por exemplo o planejamento. Segundo Ingelstam, o planejamento "representa a forma da sociedade exercer poder sobre o seu futuro, rejeitando a resignação e partindo para iniciativas que definam o seu destino". (BUARQUE, 2004, pag.81). Reforça o posicionamento, a afirmação de Sachs de que "a tecnologia constitui um lugar privilegiado, no qual podem virtualmente se harmonizar as três aspirações de equidade social, prudência ecológica e de eficácia econômica". (SACHS, 2009, pag.211). Nesse contexto o design, pela natureza da atividade, tem um papel significativo "ligando o tecnicamente possível com o ecologicamente necessário, para fazer nascer propostas que sejam social e culturalmente apreciáveis" (MANZINI \& VEZZOLI, 2005 pag. 20). E comungando com este o entendimento, o artigo reforça utilizando argumentos de outros autores para dar conta da importância do design para a sustentabilidade.

\subsection{Design e Sustentabilidade}

Autores como Bomfim (1999), Bonsiepe (2011) e Manzini (2008) entendem que a atividade de design, traz na sua práxis confirmações e/ou questionamentos sobre a cultura de uma determinada sociedade ao mesmo tempo em que expressa suas contradições. Portanto, enquanto atores sociais, os designers por lidarem com as interações entre seres humanos e artefatos, mais que qualquer outro profissional, tem papel significativo na busca de soluções, discutidas e negociadas socialmente, para construção de futuros possíveis e sustentáveis. Tal desafio se traduz no papel mediador do design para projetar lidando simultaneamente com questões que envolvem inovação e tradição, as relações entre produção e consumo e as interações entre os universos local e o global como afirma Krucken (2009).

A partir de conceitos de campos de conhecimento diversos, designers-pesquisadores ampliam sua abordagem relacionando-os a ambientes específicos, tal como pode ser observado no uso de conceitos de

\footnotetext{
${ }^{7}$ A competitividade (vantagem competitiva), contudo, não pode ser considerada como dado definitivo e inelutável, mas como algo a ser construído nas condições concretas de cada realidade. Por não se limitar ao tradicional conceito de vantagens comparativas clássicas, ligadas a dotações de recursos naturais e vocações dadas, a vantagem competitiva é um processo permanente de construção e reconstrução. (BUARQUE, Sérgio. 2004 pág.22)

${ }^{8} \mathrm{O}$ termo complexo é compreendido com base nos conceitos da teoria da complexidade, que considera a incerteza, a multiplicidade de futuros, subjetividade e cultura na compreensão do mundo atual, conforme a perspectiva de autores como Morin, Pligogine, dentre outros.
} 
sistemas, de rede e de qualidade percebida a partir do produto, do território e da comunidade, valorizando e fortalecendo territórios e saberes locais. Essa abordagem permite a construção de modelos e ferramentas que auxiliam na busca de soluções para os desafios contemporâneos lidando com desequilíbrios de ordem diversas, inclusive e especialmente nos artefatos produzidos por comunidades artesãs com alto valor cultural e simbólico e baixo valor econômico. É esse o contexto da pesquisa e o artigo discute a seguir a experiência vivenciada nos últimos dois anos no Cabo de Santo Agostinho em Pernambuco.

\subsection{A ação do Laboratório no Cabo patrocinada pela Petrobrás.}

A experiência do Laboratório na elaboração de projeto para atividades de pesquisa e extensão voltadas para o artesanato permite afirmar que as condições do patrocínio foram significativas para a realização dos resultados. Iniciando pela da proposta, o detalhamento do formulário impunha especificações e relacionamentos entre atividades, tempo e metas que explicitavam claramente as intenções e resultados previstos. Mais que isso, a possibilidade de financiamento de obras, manutenção, material permanente, de consumo e pessoal, garantiu a remuneração de técnicos e principalmente dos artesãos, até então vinculados voluntariamente aos projetos, além da complementação física de setores do Centro de Artesanato Arqto. Wilson de Queiroz Campos Júnior. O período de dois anos estabelecido para o projeto foi outro diferencial que contribuiu para a ampliação e consolidação de relações entre os artesãos, com o mercado e a consolidação das práticas de produção e gestão. Acrescente-se as demais condições a mobilidade do uso dos recursos, permitindo a ajustes sem dificuldades, a facilidade de trato com os gestores e o acompanhamento quadrimestral dos resultados.

Os recursos foram gerenciados pele Fundação de Desenvolvimento da UFPE que contratou serviços, técnicos e artesãos por dois anos para trabalhar no projeto. Com a garantia de um salário base (complementado com as vendas dos produtos), os artesãos tiveram tranquilidade para dedicar-se aos encontros semanais, discutindo desde a construção do planejamento estratégico, a melhoria dos processos produtivos, os produtos, o acesso dos produtos ao mercado e o modelo de gestão. Ao longo dos dois anos foi possível reconhecer necessidades, problemas e testar soluções, fortalecendo um ambiente de aprendizagem tanto para artesãos quanto para os técnicos.

\section{Série Histórica}

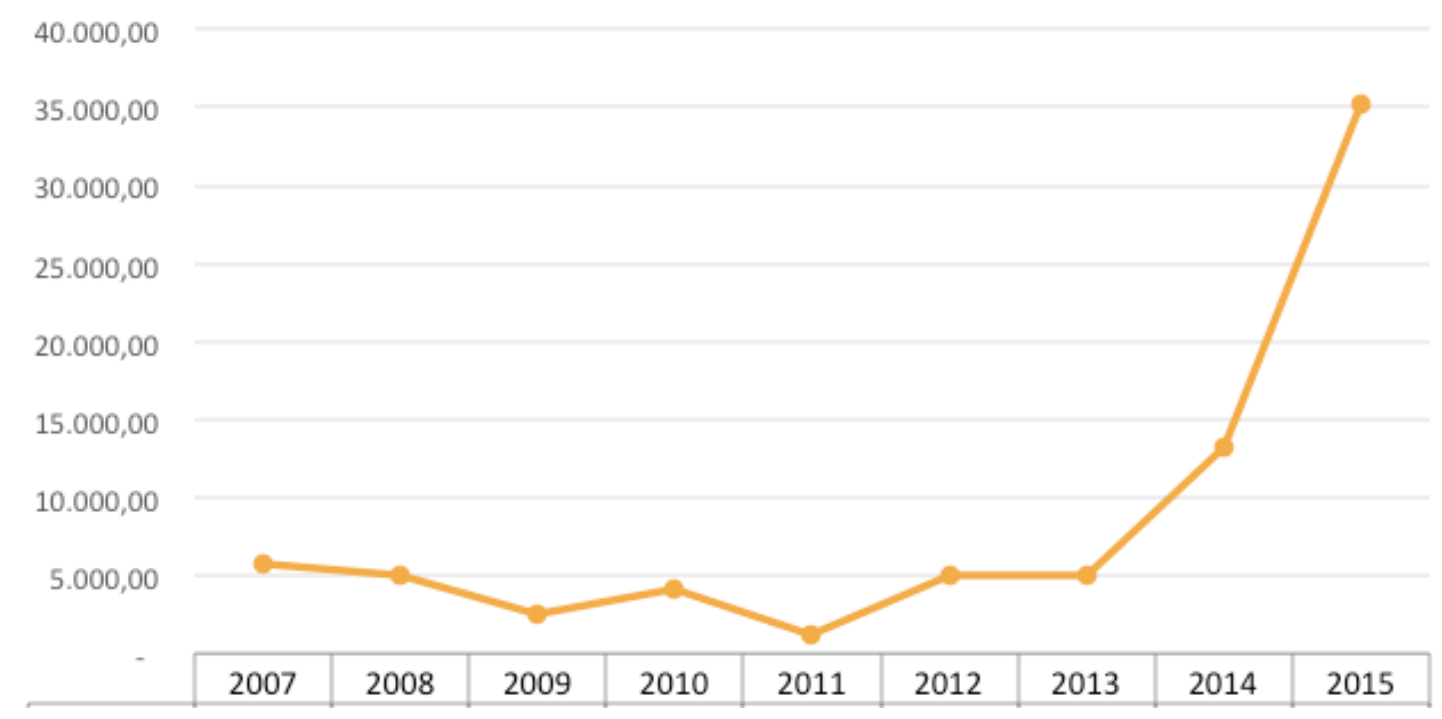

Figura 2 - Evolução das vendas na FENEARTE (2013/2015 - Período do projeto). Fonte. Petrobras, 2015. Fonte: Elaborado pelo autor, com base na pesquisa realizada 
A convivência diária dos artesãos ao mesmo tempo que reafirmou a prática das antigas olarias, (a relação dos mestres com jovens artesãos) levantou questionamentos sobre modos de gerir (pessoal e recursos) e de se relacionar com o mercado. A evolução das vendas dos produtos do Centro de Artesanato na Feira Nacional dos Negócios do Artesanato - FENEARTE, a maior feira do setor da América Latina, ilustra o impacto do projeto.( Figura 2)

O tempo também favoreceu a ampliação e consolidação de parcerias locais. Empresários da construção civil, da indústria cerâmica e do mercado varejista aproximaram-se do Centro de Artesanato apoiando a obtenção de matéria -prima, o uso de refugo industrial e a comercialização de produtos em shopping center de alta circulação e perfil de consumidor meta do projeto conforme figura 3.

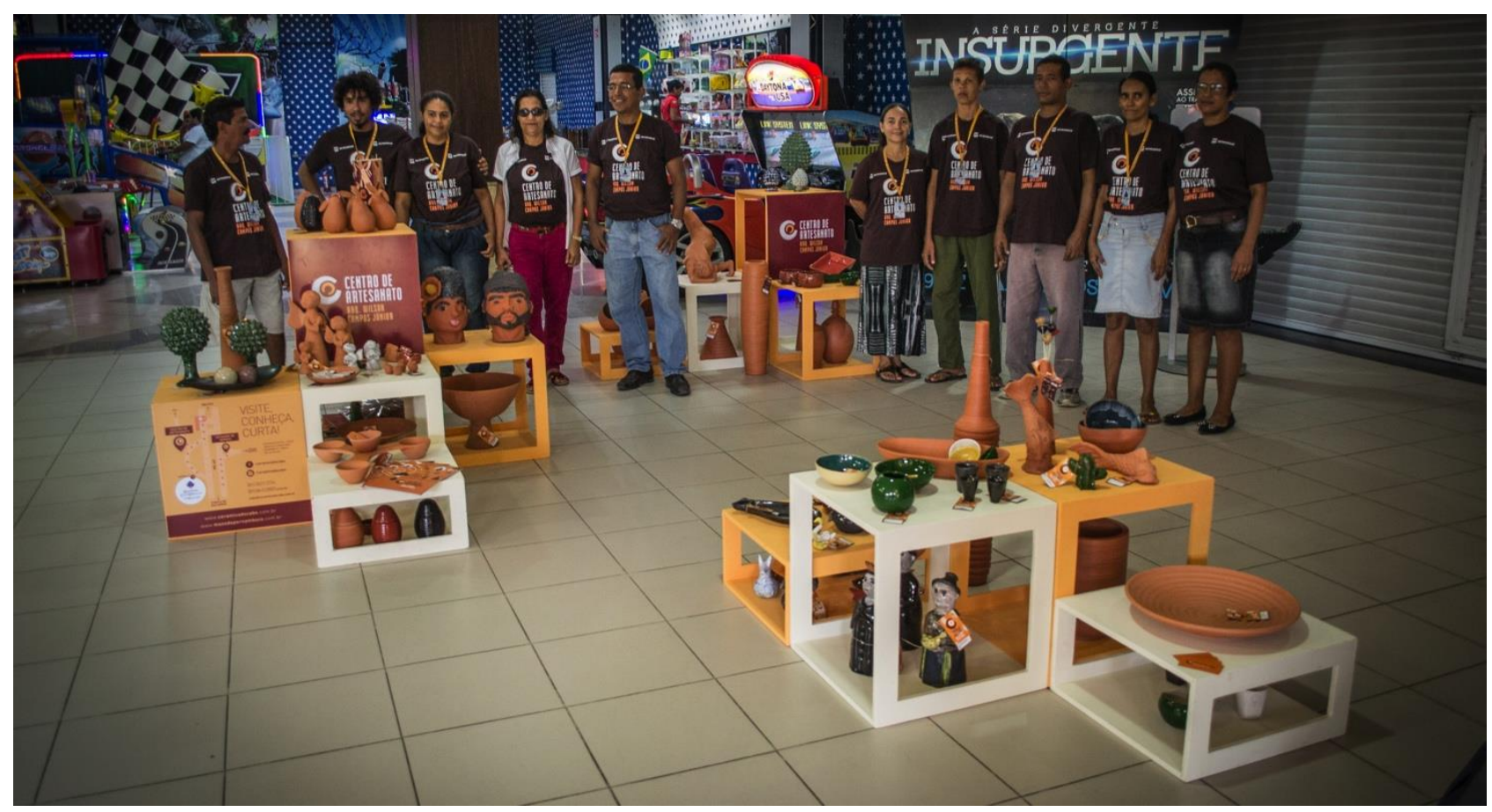

Figura 3 - Exposição de produtos no Shopping Costa Dourada. Fonte: Laboratório O Imaginário. Fonte: Elaborado pelo autor, com base na pesquisa realizada

Como resultado do conjunto das ações, durante a vigência do projeto PETROBRAS - período (2013/2015) a avaliação sob viés econômico, apresenta a taxa de crescimento da renda média do grupo de controle $13,3 \%$ ao passo que os participantes do grupo de ceramistas do projeto tiveram um crescimento médio $203,3 \%$.

A realização de oficinas para o público em geral, além de divulgar o Centro, aproximou segmentos da sociedade como os portadores de necessidades especiais e usuários de drogas. Essa realidade instigou novas parcerias públicas municipais, agora com a Secretaria da Saúde, que investe num programa de capacitação continuada.

A rede de parcerias, junto a outros grupos de artesãos que trabalham com outras tipologias, foi fortalecida com a participação conjunta em feira e eventos gerando trocas de informação e fortalecimento dos grupos de artesãos do município como um todo.

A intensa experiência vivenciada nesses dois anos foi sistematizada e tem sido objeto de estudo de pesquisas no campo do design e da gestão de design, e este artigo é parte desse esforço de refletir, criticar e buscar práticas mais eficientes para a gestão de projetos que envolvem design e artesanato. 


\section{CONCLUSÃO}

Ao tratar de artesanato e sustentabilidade o artigo sinaliza a importância da cultura e de modelos de desenvolvimentos para a atividade tanto sob o ponto de vista da geração de renda e inclusão social como para a valorização do patrimônio cultural. Entretanto, é possível observar que as ações dos governos municipais nem sempre refletem um planejamento coerente e, em geral, para agravar, não reconhecem na cultura argumentos estruturadores.

A pesquisa aponta que a relação respeitosa entre tradição - inovação é a base para ampliar as possibilidades de aprendizagem tanto sob o ponto de vista técnico, quanto social e ambiental. E nesse aspecto as universidades tem muito a contribuir tomando como tema de pesquisa e extensão o artesanato, o design e a sustentabilidade. Entretanto é importante criar nas universidades mecanismos mais eficientes para a gestão de projetos, de tal sorte que os esforços sejam destinados a atividade fim (a execução do projeto) e não a gestão dos recursos. Ações nessa direção sem dúvida motivariam professores a ampliar a interface com a sociedade.

Os últimos dois anos no Cabo de Santo Agostinho foram inspiradores, principalmente pelos resultados relacionados a sustentabilidade econômica, associados a troca de informações entre academia , (estudantes, técnicos e professores) e sociedade (artesãos, empresários e governos) civil.

Não há dúvidas que após o término do patrocínio da Petrobras o Centro de Artesanato Arqto. Wilson de Queiroz Campos Junior tem desafios a enfrentar: a remuneração daqueles não artesãos que participaram da gestão do Centro, a formalização legal, são exemplos. Entretanto é preciso contar com o patrimônio de credibilidade, construído ao longo desses anos, que tem repercutido numa rede que converge interesses de pesquisadores, artesãos, empresários e agentes governamentais para dar continuidade a essa caminhada.

\section{REFERÊNCIAS}

ANDRADE, Ana; CAVALCANTI, Virginia. Imaginário pernambucano: design, cultura, inclusão social e desenvolvimento sustentável. Recife: Zoludesign, 2006.

BOMFIM, Gustavo. Formas do Design. Rio de Janeiro: 2AB. 1999.

BONSIEPE, Gui. Design, Cultura e Sociedade. São Paulo: Blücher, 2011.

BUARQUE, Sergio. Construindo o desenvolvimento local sustentável. Metodologia de Planejamento. Rio de janeiro: Editora Garamond Ltda., 2004.

MORAES Dijon de; KRUCKEN, Lia. Design e Transversalidade. BH. Cadernos de Estudos Avançados em Design, Caderno 2, julho 2008. Santa Clara

DÁGUIAR, Rosa Freire. (org.) Celso Furtado e a dimensão Cultural do desenvolvimento. Rio de Janeiro: Epapers: Centro Internacional Celso Furtado, 2013. (Pensamento Crítico 2)

FURTADO, Celso. Quem somos. Conferência proferida no Encontro Nacional de Política Cultural. Belo Horizonte, 1984. In: d'Águiar, Rosa Freire (organização). Celso Furtado e dimensão cultural do desenvolvimento. Centro Internacional Celso Furtado. Rio de Janeiro: E-papers, 2013.

KRUCKEN, Lia. Design e Território: Valorização de identidades e produtos locais. São Paulo: Nobel, 2009.

Competência para o design na sociedade contemporânea. MORAES, Dijon de; KRUCKEN,

Lia. In Design e Transversalidade. BH. Cadernos de Estudos Avançados em Design, Caderno 2, Santa Clara. julho 2008.

MAGALHÃES, Aloísio. E Triunfo? A questão dos bens culturais do Brasil. Rio de Janeiro: Nova Fronteira; Fundação Roberto Marinho, 1997.

MANZINI, Ezio.; VEZZOLI, Carlo. O desenvolvimento de produtos sustentáveis. São Paulo: Editora da Universidade de São Paulo, 2002.

MANZINI, Ezio. Design para a inovação social e sustentabilidade. Comunidades criativas, organizações colaborativas e novas redes projetuais. Cadernos do Grupo Altos Estudos; v.1 Rio de Janeiro: E-papers, 2008

MONTIBELLER Filho, Gilberto. Ecodesenvolvimento e Desenvolvimento Sustentável. Conceitos e Princípios. Textos de Economia.V.4. n.1 pág. 131-142. 1993. Disponível em https://periodicos.ufsc.br/index.php/economia/article/viewFile/6645/6263, acesso em 18 de novembro de 2014. 
MORAES, Dijon de; KRUCKEN, Lia. Design e Transversalidade. BH. Cadernos de Estudos Avançados em Design, Caderno 2, julho 2008. Santa Clara.

MORAES, Dijon: in O papel atual do design. KRUCKEN, Lia. Design e Território - Valorização de identidades e produtos locais. São Paulo: Nobel, 2009

MORAES, Dijon. Metaprojeto. O design do design. São Paulo: Blucher, 2010.

PRIGOGINI, llya. Ciência, Razão e Paixão. Carvalho, Edgard de Assis (org.) Belém: EDUEPA, 2001.

PETROBRAS. Projeto Centro de Artesanato Arqto. Wilson de Queiroz Campos Júnior. Relatório Final, 2015.

SACHS, Ignacy. Rumo à ecossocioeconomia: teoria e prática do desenvolvimento. In: Vieira, Paulo Freire (org.). São Paulo: Cortez, 2007.

Garamond, 2009.

Caminhos para o desenvolvimento sustentável. In: Stroh, Paula Yone (org.). Rio de Janeiro: 